\title{
Impacto da urbanização nas águas superficiais de uma microbacia urbana no município de Capanema/PA, Brasil
}

Os usos múltiplos do solo têm efeitos diferentes sobre a qualidade da água, e a magnitude desses efeitos depende da área ocupada, sendo o processo desordenado de urbanização uma das causas mais comuns de impactos nos corpos hídricos nas cidades. Esta pesquisa objetivou realizar um estudo da influência da urbanização na qualidade da água da microbacia hidrografia do rio Ouricuri na cidade de Capanema - PA. Foram analisados quatro parâmetros: temperatura, oxigênio dissolvido, $\mathrm{pH}$ e sólidos totais dissolvidos. As amostras foram coletadas tomando três características: (1) amostras do rio Ouricuri, (2) de córregos urbanos e (3) de tributários. Os resultados foram avaliados com base na resolução do CONAMA no 357 de 2005. Através dos resultados dos testes estatísticos ANOVA e Tukey, identificou-se que o rio Ouricuri e os córregos demonstram evidencias de ações impactantes nas características físico-químicas e a sazonalidade surgiu como fator preponderante de diferenciação em função do $\mathrm{pH}$, assim como OD e STD em relação aos corpos hídricos analisados. O modelo de regressão gerado pelo método stepwise, evidenciou a interação entre OD e STD eficiente em predizer condições de hipóxia ou anoxia em corpos hídricos de áreas urbanas.

Palavras-chave: Qualidade de Água; Urbanização; CONAMA; Capanema-PA.

\section{Impact of urbanization on surface water in the urban watershed in the municipality of Capanema/PA, Brazil}

\begin{abstract}
Multiple land uses have different effects on water quality, and the magnitude of these effects depends on the area occupied, with the disorderly urbanization process being one of the most common causes of impacts on water bodies in cities. This research aimed to carry out a study of the influence of urbanization on water quality in the watershed of the Ouricuri river, in the city of Capanema - PA. Four parameters were analyzed: temperature, dissolved oxygen, $\mathrm{pH}$ and total dissolved solids. The samples were collected taking three characteristics: (1) samples from the Ouricuri river, (2) from urban streams and (3) from tributaries. The results were evaluated based on the CONAMA resolution No. 357 of 2005. Through the results of the ANOVA and Tukey statistical tests, it was identified that the Ouricuri river and the streams demonstrate evidence of impacting actions on the physical-chemical characteristics and seasonality emerged as a preponderant factor of differentiation according to $\mathrm{pH}$, as well as OD and STD in relation to the water bodies analyzed. The regression model generated by the stepwise method showed the interaction between OD and STD efficient in predicting hypoxia or anoxia conditions in water bodies in urban areas.
\end{abstract}

Keywords: Water Quality; Urbanization; CONAMA; Capanema-PA.

Topic: Uso Sustentável da Biodiversidade

Reviewed anonymously in the process of blind peer.
Received: 01/02/2021

Approved: 25/02/2021
Antonio Reynaldo de Sousa Costa (iD Universidade Federal Rural da Amazônia, Brasil http://lattes.cnpq.br/5860581793460787 http://orcid.org/0000-0001-9883-8423 reynaldo-sc@hotmail.com

Rafael Magalhães de Aragão (iD Universidade Federal Rural da Amazônia, Brasil http://lattes.cnpq.br/4991886853359622 http://orcid.org/0000-0001-7386-5994 rafael.aragao@ufra.edu.br

Pedro Moreira de Sousa Junior (iD) Universidade Federal Rural da Amazônia, Brasil http://lattes.cnpq.br/3194428833833524 http://orcid.org/0000-0002-6964-562X pedro.junior@ufra.edu.br

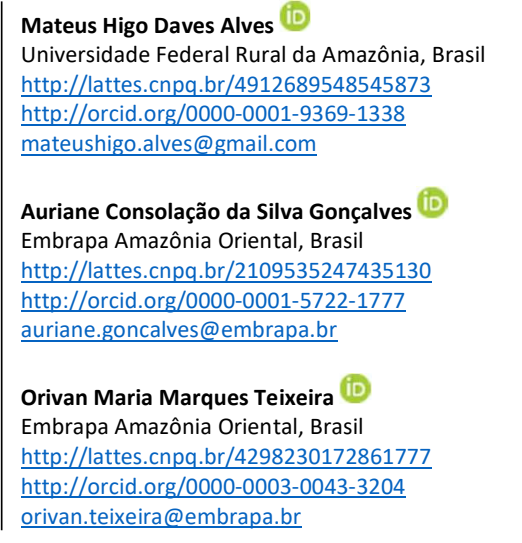

Gabrielle Costa Monteiro (iD

Universidade Federal Rural da Amazônia, Brasil http://lattes.cnpq.br/8205667465188958 http://orcid.org/0000-0003-4507-1884 monteirogabrielle57@gmail.com

Kelson do Carmo Freitas Faial (ic Instituto Evandro Chagas, Brasil http://lattes.cnpq.br/5038449535463689 http://orcid.org/0000-0001-7094-4902 kelsonfaial@iec.gov.br
DOI: 10.6008/CBPC2179-6858.2021.002.0020
Referencing this:

COSTA, A. R. S.; ARAGÃO, R. M.; SOUSA JUNIOR, P. M.; ALVES, M. H. D.; GONÇALVES, A. C. S.; TEIXEIRA, O. M. M.; MONTEIRO, G. C.; FAIAL, K. C. F.. Impacto da urbanização nas águas superficiais de uma microbacia urbana no município de Capanema/PA, Brasil. Revista Ibero Americana de Ciências Ambientais, v.12, n.2, p.203-215, 2021. DOI: http://doi.org/10.6008/CBPC2179-6858.2021.002.0020 


\section{INTRODUÇÃO}

O processo de urbanização desordenada determina impactos naturais, tanto pelas atividades econômicas quanto pela construção de vias de acesso e infraestrutura necessárias para a ocupação das populações humanas (MIRANDA et al., 2017; PIAZZA et al., 2017). Assim, a escassez ou omissão no uso do conhecimento pela construção civil sobre a preservação estratégica de ambientes naturais contribui para falhas no planejamento de cidades sustentáveis. Como resultado disso, as ações humanas aumentaram a pressão sobre os recursos naturais (AMÂNCIO et al., 2018; SILVA et al., 2018; PAIVA et al., 2020). No Brasil, são comuns problemas de saneamento básico, abastecimento municipal e proteção dos mananciais. Estes problemas estão ameaçando os usos múltiplos da água em todas as regiões (TUNDISI et al., 2020).

Na Amazônia, especificamente na região nordeste do Pará, o cenário do desenvolvimento urbano dos municípios também diverge dos modelos de planejamento sustentável. O processo de ocupação, em geral, fez-se desordenado, como por exemplo, o município de Capanema-PA, que apresenta uma história fundamentada na poluição e assoreamento dos rios locais e na substituição progressiva da floresta primitiva por áreas destinadas a ocupações econômicas (LIMA, 2015).

Os usos múltiplos do solo têm efeitos diferentes na qualidade da água e, a magnitude desses efeitos depende da área ocupada, intensidade de manejo, configuração da bacia hidrográfica, padrões de drenagem, características geológicas e geomorfológicas da bacia hidrográfica e variações sazonais (MELLO et al., 2020). Um exemplo é a poluição causada pelo contato direto com resíduos e efluentes (domésticos e/ou industriais), que está entre os impactos mais comuns nos corpos d'água perto das cidades (MARINHO et al., 2020). Além disso, o sistema de drenagem da bacia hidrográfica e o assoreamento dos rios também modificam facilmente as características químicas, físicas e biológicas da água nos corpos hídricos, comprometendo a qualidade para uso humano (PIMENTA et al., 2015; TUNDISI et al., 2008). Em termos ecológicos, as repercussões da poluição da água se materializam nos baixos níveis de oxigênio dissolvido (OD) e $\mathrm{pH}$, causados pelo aumento do metabolismo de microrganismos envolvidos na depuração dos esgotos (VON SPERLING, 2005; AMORIM et al., 2017).

Desse modo, duas considerações devem ser enfatizadas: o processo de urbanização do município de Capanema-PA aconteceu dentro da área da microbacia rio Ouricuri e atualmente ainda não existem estudos específicos da qualidade físico-química da água desta microbacia hidrográfica. Diante do exposto, faz-se necessário a realização do monitoramento dos corpos hídricos, frente a necessidade científica de diminuir no futuro, os impactos causados pelos avanços da urbanização (MARINHO et al., 2020). Diante do exposto, a pesquisa objetivou analisar a influência do uso do solo pelo processo de urbanização na qualidade da água da microbacia do rio Ouricuri, utilizando os parâmetros: OD, pH e STD.

\section{MATERIAIS E MÉTODOS}

\section{Área de estudo}

O município de Capanema, está localizado na Mesorregião do Nordeste Paraense, Microrregião 
Bragantina, a $160 \mathrm{~km}$ da capital do estado, Belém (PARÁ, 2011). A cidade nasceu e se desenvolveu submetendo gradualmente sua floresta nativa, cortada por vários rios, a mudanças cada vez mais intensas em nome do progresso. Isso consolidou a conversão da floresta em espaços para pecuária e agricultura; aterro de nascentes e poluição dos rios (LIMA, 2015).

O espaço urbano do município foi construído dentro da área da bacia hidrográfica composta pelos rios Ouricuri (rio principal), Capanema, Garrafão e Soldadinho (tributários) e córregos urbanos. O rio Ouricuri tem uma extensão total de aproximadamente $18 \mathrm{~km}$ e atravessa o município na direção leste - oeste. Este rio tem nascentes e foz localizado em áreas rurais, no entanto, $7 \mathrm{~km}$ estão localizados dentro da área urbana e regiões adjacentes da cidade (SOUZA, 2003). Os tributários estão localizados em áreas rurais e marginais da cidade de Capanema, onde sofrem impactos pontuais na geometria do leito, assoreamento e vegetação ripária de determinados locais (CAPANEMA, 2010). Por outro lado, os córregos têm nascentes localizadas na área urbana da cidade; devido a isso foram gradualmente convertidos em canais de esgoto a céu aberto. Soma-se a isso a proximidade das margens às casas, comércios e terrenos urbanos, que facilita o fluxo de águas residuais para rios do município.

\section{Amostragem e procedimentos de coleta}

Vieira et al. (2018) comentam que a cidade de Capanema possui um perfil climático, no qual os meses de janeiro a junho tem maiores precipitações e, por isso, caracteriza-se como período da estação chuvosa (EC); já os meses de julho a dezembro que apresentam as menores precipitações e, portanto, designa-se como estação pouco chuvosa (EPC). A primeira campanha de coleta de água ocorreu em janeiro de 2018, enquanto a segunda ocorreu em dezembro de 2018, sendo que todas as coletas ocorreram em um dia. Em 2018, a EC registrou um volume acumulado de 1.856,2 mm de chuvas; já a EPC registrou 653,3 mm (INMET, 2018). Todo o procedimento de coleta de amostras ocorreu de acordo com o Standard methods for the examination of water and wastewater (APHA, 2005).

A Figura 1 apresenta o mapa do município de Capanema contendo dezoito pontos de coleta de água referenciados com auxílio do equipamento GPS MAP 76CSx - Garmin. A pesquisa efetuou medições in situ dos parâmetros: $\mathrm{pH}$, temperatura, OD e STD; com uso da sonda multiparâmetro modelo Bante 900P fabricado pela Bante Instruments, conforme protocolos propostos por Ribeiro et al. (2016), Pereira et al. (2016), Silva et al. (2017) e Peluso et al. (2020). Todos os eletrodos foram devidamente calibrados conforme metodologia descrita no manual do aparelho. Posteriormente, os resultados mensurados foram conferidos e discutidos com base nos padrões dos parâmetros estabelecidos na legislação. A portaria no 357/2005 do CONAMA define em seu artigo 42 que "enquanto não aprovados os respectivos enquadramentos, as águas doces serão consideradas classe $2[\ldots]^{\prime \prime}$; essa classe de águas doce determina os limites mínimos de: $5 \mathrm{mg} \mathrm{L}^{-1}$ para o OD; $500 \mathrm{mg} \mathrm{L}^{-1}$ para o STD e um pH dentro da faixa de 6,0 a 9,0 (BRASIL, 2005). 


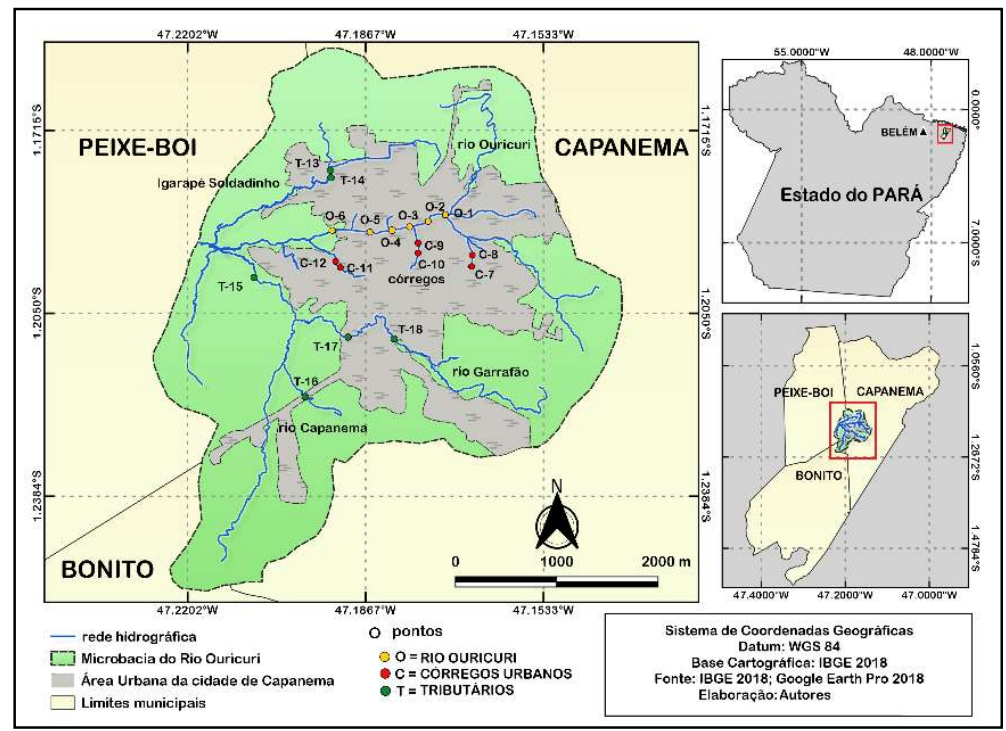

Figura 1: Pontos amostrados na Microbacia do Rio Ouricuri.

\section{Tratamento dos dados}

\section{ANOVA com dois fatores}

A pesquisa foi realizada com delineamento em blocos ao acaso, e esquema fatorial $3 \times 2$ com três repetições. $\mathrm{O}$ primeiro fator foi composto por águas coletadas em diferentes corpos hídricos e o segundo fator foi composto pelo período climático (EC e EPC). A escolha do processamento estatístico procedeu mediante exame dos dados quanto as premissas de normalidade e homocedasticidade da variância usando, respectivamente, os testes Shapiro-Wilk e Levene. O mesmo procedimento também foi realizado por TablaHernandez et al. (2020) para avaliar e comparar a qualidade da água: antes, durante e após tratamento. Apoiado nos estudos de Piratoba et al. (2017), Loucif et al. (2020) e Marinho et al. (2020), optou-se pelo teste de Análise de Variância (ANOVA) contendo dois fatores com três repetições para analisar a influência das variáveis independentes categóricas, sazonalidade e corpo hídrico, nas variáveis dependentes pH, OD e STD (MOLUGARAM et al., 2017). Quando detectado efeito significativo, foi realizado o teste post hoc de Tukey, adotando-se um nível de significância de $p \leq 0,05$ para localizar as diferenças.

\section{Análise de Regressão}

Através de versão no 20.0.0, do software Statistical Package for Social Sciences (SPSS), foi elaborado uma análise de regressão com intuito de estabelecer a função matemática mais adequada para unir a ou as variáveis independentes à variável dependente - oxigênio dissolvido. Para tanto, a seleção de variáveis ocorreu mediante cálculo automático de modelos com o método de busca gradativa stepwise e o critério de inclusão ou remoção de variáveis no modelo foi a partir da significância de F (GOTELLI et al., 2011). Posteriormente, o modelo gerado foi validado mediante a coleta de novos dados, a fim de testar a eficiência. 


\section{RESULTADOS E DISCUSSÃO}

\section{Análise do ph}

Inicialmente foi realizado o teste de box-plot (Figura 2) a fim de identificar padrões de comportamento entre as áreas correspondentes ao rio Ouricuri, córregos e tributários nas estações chuvosa e pouco chuvosa. Comparando os resultados com a prescrição do CONAMA para pH, os menores valores encontrados no estudo foram observados no rio Ouricuri, variando de 6,71 a 7,21, com média de 6,93 na EC e variação de 5,02 a 6,25, com média de 5,84 na EPC. No entanto, os maiores valores desse parâmetro foram observados na EC nos tributários, com variação de 6,91 a 7,53 e média de 7,22. Os córregos urbanos apresentaram valores intermediários no estudo, sendo a média de 6,98 na EC e 6,19 na EPC. Em geral, os resultados ilustram um desvio padrão variando de $\pm 0,22$ a $\pm 0,47$ e isso pode evidenciar uma resistência moderada da água em relação à influência de impactos locais no parâmetro.

As análises evidenciam os maiores valores deste parâmetro na EC, em todos os locais analisados quando comparado a EPC; nesta última, prevaleceram valores de $\mathrm{pH}$ ligeiramente ácidos. A redução no volume de água associado à diminuição do poder de diluição exercido pelas chuvas e ao aumento da concentração de efluentes, podem ter contribuído para a redução do pH no período menos chuvoso. Nos estudos de Paiva et al. (2015), as médias de pH também foram maiores no período chuvoso do que no período seco e Amorim et al. (2017) observaram águas levemente ácidas com discreto aumento de pH no período seco em Bacabeira - MA.

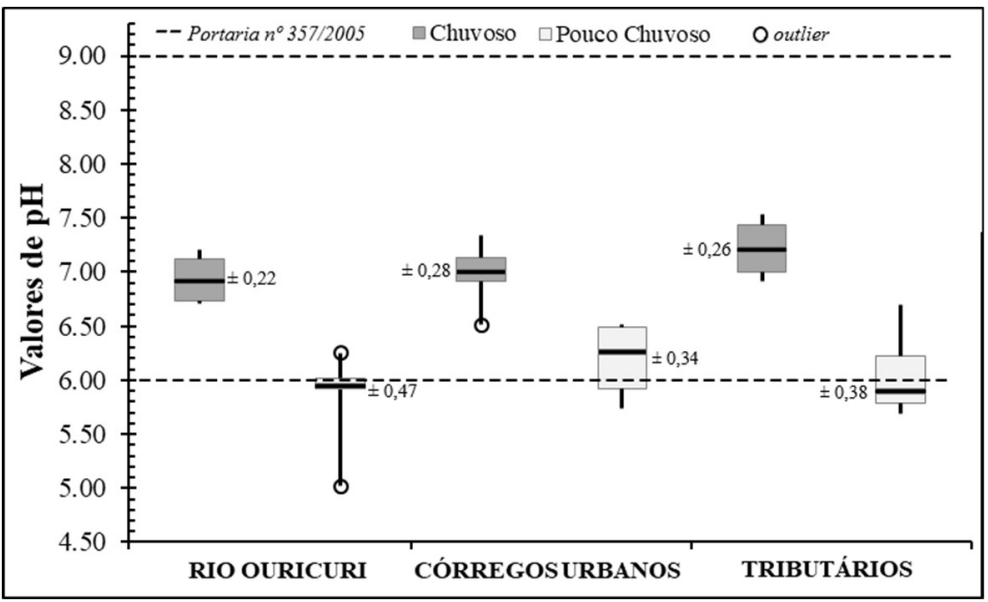

Figura 2: Análises de pH em diferentes corpos hídricos em função das EC e EPC.

Embora os rios amazônicos, em geral, possuam características ácidas devido aos efeitos do solo e dos produtos do metabolismo da fauna e da flora, conforme apontado por Sioli et al. (1962), os resultados do pH mensurados neste estudo, demonstraram a influência da geologia nos atributos hidrológicos e biológicos da região, observada por Pereira et al. (2016) e Oliveira Filho et al. (2018).

Os valores 6,25 e 5,02, encontrados respectivamente nos pontos 1 e 2 do rio Ouricuri na EPC, foram considerados atípicos. A água que chega ao ponto 1 recebe grande influência do curso do rio que atravessa um terreno de clube esportivo no qual não foram observadas ações antropogênicas impactando-a. Esse resultado demonstra a capacidade de assimilação ou a autopurificação deste trecho do rio, diluindo os 
impactos da vizinhança na qualidade da água (MIR et al., 2019). Bem diferente do que foi observado na área em torno do ponto 2 , onde ambas as margens tinham casas e comércios despejando diretamente efluentes no curso do rio e isso pode ter contribuído para a diminuição do $\mathrm{pH}$. Outro valor atípico $($ valor 6,50$)$ foi observado no ponto 12 durante a EC, e o mesmo foi relacionado ao fato de encontrar-se em um canal de córrego que recebe alto fluxo de efluentes.

Em relação a Portaria № 357 do CONAMA, o presente estudo constatou que, exceto o rio Ouricuri no período pouco chuvoso, as águas desta microbacia apresentaram valores médios de $\mathrm{pH}$ de acordo com os estipulados na classe 2 de água doce. A World Health Organization - WHO - (2017), salienta que o pH ideal da água está geralmente na faixa de 6,5 - 8,5. Valores que, conforme Libânio (2010), estão adequados às exigências da maioria das espécies de organismos.

\section{Análise do oxigênio dissolvido}

A temperatura média da água observada no estudo foi de 26,7 ㄷ C na estação chuvosa e 26,1 ㅇ $\mathrm{C}$ na pouco chuvosa, em todos os pontos coletados. Essa baixa amplitude térmica não afetou sazonalmente as taxas de oxigênio dissolvido. Comportamento semelhante foi observado no estudo de Tabla-Hernandez et al. (2020), no qual a temperatura não apresentou uma variação significativa capaz de influenciar os parâmetros de qualidade da água. A Figura 3 ilustra o gráfico box-plot gerado a partir dos resultados do parâmetro OD nas EC e EPC, nos corpos d'água estudados. Os resultados mostram que os córregos urbanos apresentaram os menores valores e maiores desvios-padrão para ambas estações, sendo esta variação de 1,11 a 3,96 $\mathrm{mg} \mathrm{L}^{-1}$ na EC e 0,51 a 5,02 $\mathrm{mg} \mathrm{L}^{-1}$ na EPC. A falta de uma rede de esgoto adequada pode exercer forte pressão sobre a qualidade da água, pois afeta principalmente a autodepuração dos corpos d'água (PIAZZA et al., 2017; SILVA et al., 2017; JESUS et al., 2019). Portanto, os valores mensurados não alcançam a média do limite inferior de $5 \mathrm{mg} \mathrm{L}^{-1}$ estipulado na legislação. $O$ rio Ouricuri apresentou as médias de 4,87 mg $\mathrm{L}^{-1}$ na EC e 5,32 $\mathrm{mg} \mathrm{L}^{-1}$ na EPC, dessa forma, configurando desacordo com a referência de OD na legislação no período chuvoso. O rio também demonstrou os menores desvios-padrões do parâmetro no estudo. Os maiores valores deste parâmetro no estudo foram encontrados nos tributários com as médias de $6,17 \mathrm{mg} \mathrm{L}^{-}$

${ }^{1}$ na estação chuvosa e 5,31 mg L ${ }^{-1}$ na pouco chuvosa. Portanto, os tributários encontram-se classificados na classe 2 de água doce, conforme a referida legislação do CONAMA. A concentração de oxigênio dissolvido é um indicador importante para avaliar a qualidade da água (MULLER et al., 2016). Além disso, trata-se de um fator limitante para muitas espécies aquáticas, uma vez que, suas variações impactam diretamente na respiração celular destes organismos (JESUS et al., 2019). Os resultados de OD mostraram que os córregos e o rio Ouricuri apresentaram os maiores teores na EPC quando comparados à EC. Devido ambos os corpos d'água serem localizados na área urbana a redução das chuvas diminui o contato com a matéria orgânica e inorgânica oriundas da cidade e isso contribuiu para reduzir as reações que consomem oxigênio nesses ambientes. Frequentemente, estudos que investigam a qualidade da água encontram baixos valores de OD nos locais em áreas antropizadas (SOUZA et al., 2015; PEREIRA et al., 2016; MARINHO et al., 2020). Entretanto, os rios tributários apresentaram maiores valores de OD na EC em comparação com a EPC; nesse 
caso, o aumento da vazão causado pelo volume de água pode explicar os altos teores de oxigênio na água. Essa influência da vazão também foi observada no estudo de Silva et al. (2018) no município de Salinópolis PA. Outros fatores que podem ter influenciado o comportamento desse parâmetro foram: o pequeno tamanho entre as margens (entre 5 a 10 metros ao longo de todo o comprimento), a vazão reduzida e o fraco movimento de fluxo de água. Estudos realizados por de Garcia et al. (2018) associaram baixos valores de OD à pequena profundidade. Em outro estudo foi de observado que os maiores valores de OD estavam associados a áreas pouco urbanizadas, semelhante ao presente estudo Menezes et al. (2016).

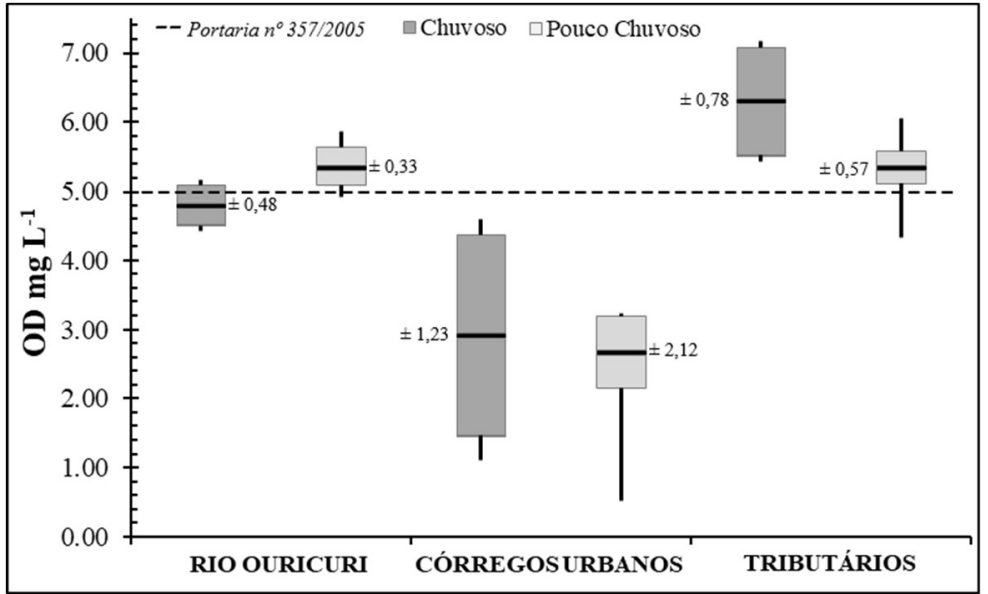

Figura 3: Análises de OD em diferentes corpos hídricos em função da EC e EPC.

\section{Análise dos sólidos totais dissolvidos}

Os gráficos box-plot e os respectivos desvios-padrão obtidos com os resultados do parâmetro STD nas estações chuvosa e pouco chuvosa nos corpos d'água da microbacia do rio Ouricuri, são mostrados na Figura 4. Em geral, esse parâmetro é altamente influenciado pelas mudanças nos índices de chuvas. Quando em excesso no leito dos rios, esses compostos são capazes de alterar a qualidade da água e podem causar assoreamento do curso d'água (GARCIA et al., 2018). Os resultados de STD apontaram que, os maiores valores ocorreram nos córregos urbanos com média de 440,17 $\mathrm{mg} \mathrm{L}^{-1}$, variando de 362,67 a 565,36 mg L ${ }^{-1}$ na estação chuvosa e média de 358,93 $\mathrm{mg} \mathrm{L}^{-1}$, variando de 119,29 a 535,93 $\mathrm{mg} \mathrm{L}^{-1}$ na pouco chuvosa. Portanto, os resultados exibiram valores superiores ao limite máximo de $500 \mathrm{mg} \mathrm{L}^{-1}$, conforme prescrito na resolução do CONAMA. O rio Ouricuri aparece com os segundos maiores teores; registrando um valor médio de 237,12 mg L ${ }^{-1}$ na estação chuvosa e $190,73 \mathrm{mg} \mathrm{L}^{-1}$ na pouco chuvosa. Valores elevados de STD, são geralmente encontrados em corpos d'águas presentes em áreas densamente urbanizadas (FERREIRA et al., 2015; MENEZES et at., 2016; OLIVEIRA et al., 2018). Há uma alta descarga de efluentes domésticos e industriais sem tratamento nesses lugares, o que contribui para o aumento dos sólidos totais dissolvidos na água (ESTEVES, 2011; SILVA et al., 2017; MEDEIROS et al., 2018). Os tributários obtiveram os níveis mais baixos nos dois períodos, sendo o valor médio de $51,51 \mathrm{mg} \mathrm{L}^{-1}$ medido na estação chuvosa e de $108,22 \mathrm{mg} \mathrm{L}^{-1}$ na pouco chuvosa; desta forma, configurando-se de acordo com a legislação e com taxas bem inferiores às observados nos outros corpos d'água. 


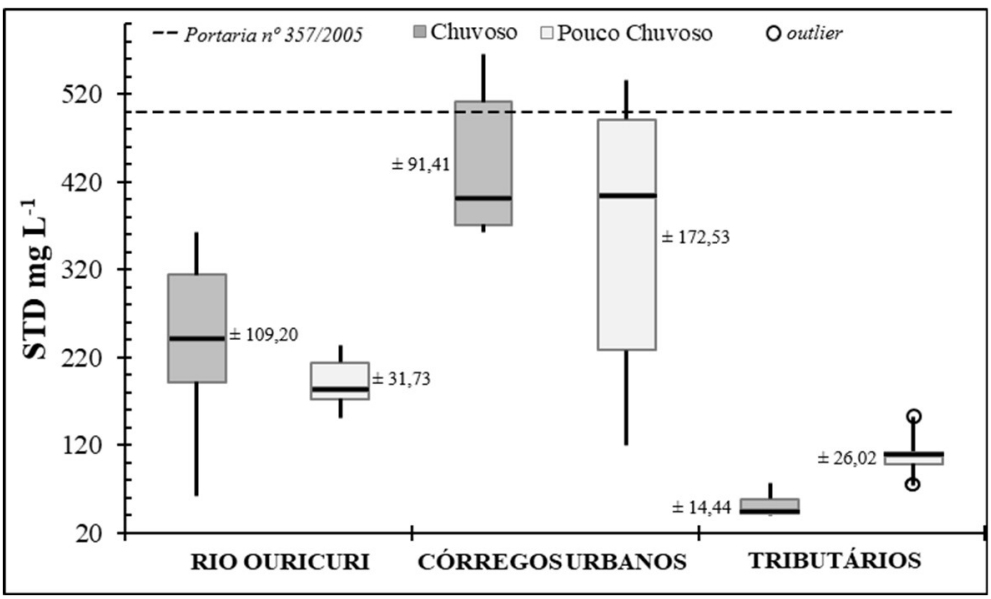

Figura 4: Análises de STD em diferentes corpos hídricos em função da EC e EPC.

O maior volume de chuvas influenciou um aumento nos teores de sólidos totais dissolvidos no rio Ouricuri e nos córregos quando observado a EC em relação à EPC. A precipitação também foi um fator que aumentou a quantidade de sólidos totais dissolvidos nos estudos de Silva et al. (2018) e Amâncio et al. (2018). O estudo de Silva et al. (2016) sobre macroinvertebrados em trechos urbanos de corpos d'água no Município de Capanema, encontrou evidências de que a presença de moradias e atividades humanas próximas às áreas de margens estão degradando a qualidade da água. Os sólidos totais dissolvidos são indicadores importantes de ações antrópicas locais ou eventos climáticos (SILVA et al., 2017). Entretanto, essa influência da cidade não ocorreu com intensidade significativa nos tributários, onde houve aumento das taxas de STD na estação pouco chuvosa em relação à chuvosa.

Observando os resultados do teste ANOVA, mostrado na Tabela 1, verifica-se que não houve efeito significativo do fator corpo hídrico ou da interação entre os fatores para o parâmetro pH. No entanto, ocorre um efeito significativo $(p \leq 0,05)$ do fator sazonalidade. Em relação ao parâmetro $O D$, houve efeito estatisticamente significativo no fator corpo hídrico, porém, não houve efeito do fator sazonalidade ou da interação entre os fatores no parâmetro. Fato semelhante ocorreu nos resultados do parâmetro STD, que indicou que não houve efeito dos fatores sazonalidade e interação, no entanto, o fator corpo hídrico promoveu influência estatisticamente significante $(p \leq 0,05)$ nos valores do parâmetro. Uma vez que o teste ANOVA indicou que há efeitos de fatores nos resultados, o teste Tukey foi realizado e seus resultados (Tabela 2), na qual confirma que a sazonalidade influenciou estatisticamente o parâmetro pH das amostras com relação ao $\mathrm{OD}$, o teste confirmou que os corpos d'água rio Ouricuri e tributários não diferem quando comparados, no entanto, ambos os corpos hídricos citados anteriormente, diferem estatisticamente dos córregos urbanos. Os resultados de STD mostraram que os tributários diferem do rio Ouricuri e dos córregos urbanos e o rio Ouricuri, por sua vez, também difere quando comparado aos córregos urbanos. No entanto, a sazonalidade não influencia significativamente o parâmetro.

O estudo de Souza et al. (2015), que avaliou a influência da área urbana sobre a qualidade da água na bacia hidrográfica de Ribeirão dos Poços - MG, também não encontrou influência estatística dos locais no parâmetro pH, no entanto, observou que eles influenciam os parâmetros OD e STD; já o fator sazonalidade influenciou significativamente para os três parâmetros no estudo. Piratoba et al. (2017) estudando a água na 
área portuária de Barcarena - PA, descobriram que os locais avaliados não influenciaram o pH da água. No entanto, foi detectada influência da sazonalidade no parâmetro, semelhante ao observado no presente estudo. Contudo, no mesmo estudo, os autores observaram que o parâmetro STD foi significativamente influenciado tanto pelo fator sazonalidade, quanto pelo fator local de coleta. Este comportamento foi distinto ao observado neste presente estudo. O estudo de Marinho et al. (2020) analisou a ação urbana no canal Água Cristal em Belém - PA e não observou influência para os parâmetros pH e OD, mas revelou influência no parâmetro STD. No entanto, o mesmo estudo não observou influência do fator sazonalidade nos três parâmetros de qualidade da água. Por fim, o estudo de Loucif et al. (2020) realizado na Argélia, não observou que os fatores localidade, mês de coleta e a interação dos fatores influenciando os parâmetros pH e OD nas águas do lago Tonga.

Tabela 1: Resultados da ANOVA com dois fatores.

\begin{tabular}{llll}
\hline Parâmetros & Efeito & $\mathbf{F}$ & valor-P \\
\hline \multirow{3}{*}{ Ph } & Corpo hídrico & 1,79 & 0,18 \\
& Sazonalidade & 86,37 & $<\mathbf{0 , 0 0 0 1}$ \\
& Interação & 1,11 & 0,34 \\
\hline \multirow{2}{*}{ OD } & Corpo hídrico & 20,68 & $<0,0001$ \\
& Sazonalidade & 0,56 & 0,36 \\
\hline \multirow{3}{*}{ STD } & Interação & 2,89 & 0,10 \\
& Corpo hídrico & 35,72 & $<0,0001$ \\
& Sazonalidade & 0,54 & 0,54 \\
\hline
\end{tabular}

Legenda: Resultados em itálico são estatisticamente significantes a nível de probabilidade de $p \leq 0,05$.

Tabela 2: Resultado do teste post hoc de Tukey.

\begin{tabular}{llll}
\hline Parâmetros & Locais & $E C$ & $E P C$ \\
\hline \multirow{3}{*}{ PH } & rio Ouricuri & $\mathrm{Aa}$ & $\mathrm{Ab}$ \\
& córregos urbanos & $\mathrm{Aa}$ & $\mathrm{Ab}$ \\
\hline \multirow{3}{*}{ OD } & Tributários & $\mathrm{Aa}$ & $\mathrm{Ab}$ \\
& rio Ouricuri & $\mathrm{Aa}$ & $\mathrm{Aa}$ \\
\hline & córregos urbanos & $\mathrm{Ba}$ & $\mathrm{Ba}$ \\
$\mathrm{N}$ STD & Tributários & $\mathrm{Aa}$ & $\mathrm{Aa}$ \\
& rio Ouricuri & $\mathrm{Ba}$ & $\mathrm{Ba}$ \\
& córregos urbanos & $\mathrm{Ca}$ & $\mathrm{Ca}$ \\
\hline
\end{tabular}

Legenda: Diferentes letras minúsculas representam a estatística dentro do corpo d'água e diferentes letras maiúsculas entre os diferentes corpos d'águas a probabilidade $p \leq 0,05$.

\section{Modelo estatístico de predição}

Para medir a natureza e extensão das correlações entre as variáveis estudadas, realizou-se a análise de regressão (MOLUGARAM et al., 2017) nos resultados dos parâmetros de qualidade de água dos diferentes corpos d'água na microbacia. Em vista disso, o método de seleção stepwise formulou duas equações de previsão e o critério para inclusão de variáveis independentes se baseou em valores de probabilidade $\mathrm{F} \leq$ 0,05 enquanto para remoção $F \geq 0,10$. Desse modo, de acordo com a Tabela 3, o Sig. $F(0,001)$ no modelo 1 que, contemplou apenas a variável independente STD, atendeu o pressuposto de inclusão $p \leq 0,05$ e evidencia que essa variável exerce influência estatística sobre a variável dependente OD e o modelo é significativo para a predição de oxigênio dissolvido. Entretanto, o modelo 2 que apresenta as variáveis 
independentes STD e pH, o Sig. F $(0,191)$ não é estatisticamente significativo e constata que esse modelo não difere do anterior. Portanto, estes dados corroboram a força de atuação da variável STD em promover variação da variável OD na microbacia.

Tabela 3: Resumo dos Modelos de Regressão formulados pelo método Stepwise.

\begin{tabular}{|c|c|c|c|c|c|c|c|c|c|}
\hline Modelo & $\mathbf{R}$ & $\mathbf{R}^{2}$ & $\begin{array}{l}\mathbf{R}^{2} \\
\text { Ajustado }\end{array}$ & $\begin{array}{l}\text { Erro } \\
\text { Padrão }\end{array}$ & $\mathbf{F}$ & df1 & df2 & Sig. $F$ & $\begin{array}{l}\text { Durbin- } \\
\text { Watson }\end{array}$ \\
\hline $1^{a}$ & 0,83 & 0,69 & 0,68 & 0,93 & 74,64 & 1 & 34 & 0,001 & \\
\hline $2^{b}$ & 0,84 & 0,70 & 0,68 & 0,92 & 1,78 & 1 & 33 & 0,191 & 1,614 \\
\hline
\end{tabular}

Preditores: $\mathrm{a}=$ Constante e STD; $\mathrm{b}=$ Constante, STD e $\mathrm{pH}$.

$O$ coeficiente de correlação $(R=0,83)$ reflete o grau de associação entre a variável dependente $O D$ e a variável independente STD. $O$ resultado apresentado na Figura 5A, monstra a moderada relação negativa e o coeficiente de determinação $\left(R^{2}=0,69\right)$, indica que $69 \%$ da variação na variável dependente OD é explicado pela variação na variável independente STD, em todos os corpos d'água na microbacia. Todavia, outros fatores não abordados podem explicar os 31 \% restantes da variação. Possivelmente, os volumes de sólidos totais dissolvidos resultantes da poluição urbana aumentaram a demanda química e biológica de oxigênio e isso contribui para a redução do nível de OD nos mananciais. Medeiros et al. (2018) não observaram correlação do OD com STD nas águas da bacia hidrográfica do rio Longá no Estado do Piauí. No entanto, foi observado forte correlação negativa de OD e STD na estação de estiagem, no estudo de Ribeiro et al. (2016). Verifica-se na Figura 5B que os erros dos resíduos se distribuem entre -2.6 e 2.6 e não se observa padrão evidente de que haja aumento sistemático dos resíduos com o aumento ou diminuição nas concentrações da variável estimada. Portanto, dessa maneira os erros são distribuídos aleatoriamente em torno de zero.
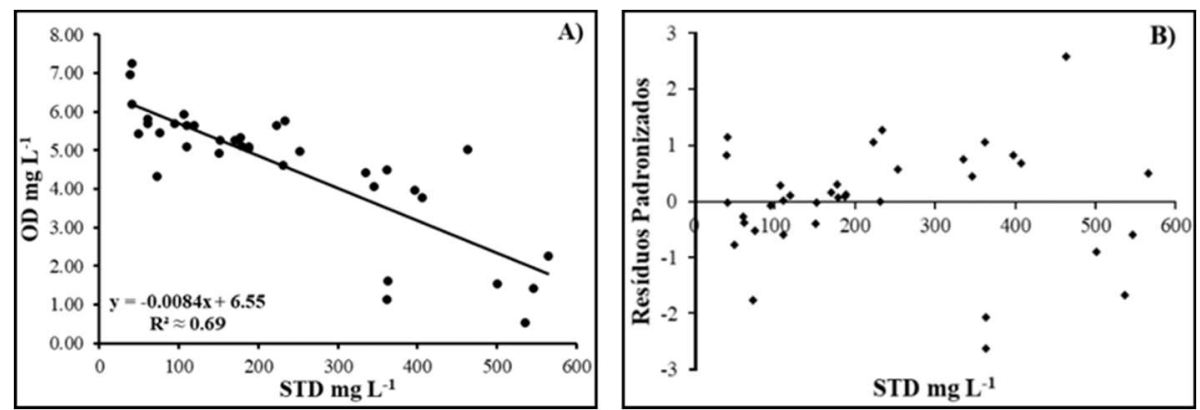

Figura 5: A) Regressão entre os dados de STD e OD e B) Dispersão entre resíduos e STD.

O valor previsto para cada observação é o valor da constante $(6,550)$, somado com o coeficiente de regressão do STD $(-0,008)$ multiplicado pelo valor da variável independente. A Tabela 4 apresenta o desempenho da equação gerada para a estimativa do parâmetro OD através de resultados de STD da água de locais coletado em abril de 2019. A análise de regressão demonstrou que à medida que aumenta a quantidade de STD na água, os teores de OD tendem a diminuir. Com isso, o modelo desenvolvido se mostrou eficiente em indicar quantitativamente o oxigênio dissolvido na água e, deste modo, retrata a forte relação desse parâmetro com os sólidos totais dissolvidos na água local. 
Tabela 4: Desempenho do modelo na previsão do OD.

\begin{tabular}{|c|c|c|c|c|c|}
\hline Modelo & Locais abril/2019 & STD observado & OD observado & OD previsto & Eficiência \% \\
\hline \multirow{6}{*}{$Y=-0,0084 x+6,55$} & P 1 & 40,08 & 5,20 & 6,21 & 80,58 \\
\hline & P 6 & 117,97 & 5,04 & 5,56 & 89,68 \\
\hline & P 10 & 312,00 & 3,72 & 3,93 & 94,35 \\
\hline & P 11 & 264,55 & 4,94 & 4,33 & 87,65 \\
\hline & P 13 & 447,85 & 5,23 & 2,79 & 53,35 \\
\hline & P 15 & 285,02 & 4,45 & 4,16 & 93,48 \\
\hline \multicolumn{2}{|c|}{ Média da eficiência \% } & & & & 83,18 \\
\hline
\end{tabular}

\section{CONCLUSÕES}

Este estudo apresentou evidencias de que o rio Ouricuri e os córregos urbanos são influenciados por ações impactantes conforme constatado pelo comportamento dos parâmetros físico-químicos de qualidade da água estudados. Quando confrontados os dados com a portaria no 357 de 2005 do CONAMA, verificou-se que apenas os tributários estão em completo alinhamento com condições prescritas na legislação referente a classe 2 de água doce.

As análises estatísticas evidenciaram que a sazonalidade influenciou o parâmetro $\mathrm{pH}$ e as características locais nos corpos d'água afetaram significativamente os níveis de oxigênio e sólidos totais dissolvidos na água. Portanto, a proximidade dos corpos d'água com as áreas urbanizadas favorecem o contato da água com grandes cargas de efluentes domésticos e/ou industriais que contribuem para que ocorram acentuadas variações nos parâmetros STD e OD. O modelo matemático gerado atendeu os pressupostos conceituais exigidos pela regressão e apresentou eficiência preditiva de aproximadamente 83\% na validação com os dados coletados em 2019

\section{REFERÊNCIAS}

AMÂNCIO, D. V.; COELHO, G.; MARQUES, R. F. P. V.; VIOLA, M. R.; MELLO, C. R.. Qualidade da água nas sub-bacias hidrográficas dos rios Capivari e Mortes, Minas Gerais. Scientia Agraria, Curitiba, v.19, n.1, p.75-86, 2018. DOI: http://dx.doi.org/10.5380/rsa.v19i1.53175

AMORIM, D. G.; CAVALCANTE, P. R. S.; SOARES, L. S.; AMORIM, P. E. C.. Enquadramento e avaliação do índice de qualidade da água dos igarapés Rabo de Porco e Precuá, localizados na área da Refinaria Premium I, município de Bacabeira (MA). Eng. Sanit. Ambient., Curitiba, v.22, n.2, p.251-259, 2017. DOI: https://doi.org/10.1590/s1413$\underline{41522016131212}$

APHA. American Public Health Association. Standard Methods for the Examination Water and Wastewater. 21 ed. Washington: APHA, 2005.

BILGIN, A.. An assessment of water quality in the Coruh Basin (Turkey) using multivariate statistical techniques. Environ Monit Assess, v.187, n.721, 2015. DOI: https://doi.org/10.1007/s10661-015-4904-9

BRASIL. Resolução CONAMA n. 357, de 17 de julho de 2005. Dispõe sobre a classificação dos corpos de água e diretrizes ambientais para o seu enquadramento, bem como estabelece as condições e padrões de lançamento de efluentes, e dá outras providências. Brasília: DOU, 2005.
CAPANEMA. Plano Ambiental do Município de Capanema. Capanema: SEMMA, 2010.

ESTEVES, F. A.. Fundamentos de Limnologia. 3 ed. Rio de Janeiro: Interciência, 2011.

FERREIRA, C. S.; CUNHA-SANTINO, M. B.; JÚNIOR, I. B.. Eutrofização: aspectos conceituais, usos da água e diretrizes para a gestão ambiental. Revista Ibero-Americana de Ciências Ambientais, Aquidabã, v.6, n.1, p.78-94, 2015. DOI: https://doi.org/10.6008/SPC2179-6858.2015.001.0006

GARCIA, J. M.; MANTOVANI, P.; GOMES, R. C.; DEMANBORO, A. C.; BETTINE, S. C.. Degradação ambiental e qualidade da água em nascentes de rios urbanos. Soc. Nat., Uberlândia, v.30, n.1, p.228-254, 2018. DOI:

http://dx.doi.org/10.14393/SN-v30n1-2018-10-

GOTELLI, N. J.; ELLISON, A. M.. Regressão. In: GOTELLI, N. J.; ELLISON, A. M.. Princípios de Estatística em Ecologia. Porto Alegre: Artmed, 2011. p.257-306.

INMET. Instituto Nacional de Meteorologia. BDMEP - Banco de Dados Meteorológicos para Ensino e Pesquisa. Dados Históricos. INMET, 2018.

JESUS, V. C.; BARRETO, H. N.; BEZERRA, A. R.; AMADOR, R. 
B.. Avaliação da qualidade da água superficial em bacias urbanas da Ilha do Maranhão. REGNE, v.5, p.54-72, 2019. DOI: http://doi.org/10.21680/2447-3359.2019v5n0ID18455

LIBÂNIO, M.. Fundamentos de qualidade e tratamento de água. 3 ed. Campinas: Átomo, 2010.

LIMA, L. D. B.. Como era verde a "mata azarada": analisando a formação de Capanema através da história ambiental. In: LIMA, L. D. B.. Dos trilhos às rodas: Histórias e memórias de Capanema. Belém: Paka-Tatu, 2015. p.149-196.

LOUCIF, K.; NEFFAR, S.; MENASRIA, T.; MAAZI, M. C.; HOUHAMDI, M.; CHENCHOUNI, H.. Physico-chemical and bacteriological quality assessment of surface water at Lake Tonga in Algeria. Environmental Nanotechnology, Monitoring \& Management, v.13, p.100284, 2020. DOI: https://doi.org/10.1016/i.enmm.2020.100284

MARINHO, E. R.; MOREIRA, F. S. A.; BRITO, W. J. P.; MOREIRA, F. L. B. B.; SILVA, E. R. M.; SANTOS, L. F.. Avaliação da Ação Urbana no Canal Água Cristal em Belém, Pará, um Estudo Sobre Qualidade da Água. Revista Brasileira de Geografia Física, v.13, n.01, p.322-335, 2020. DOI: http://doi.org/10.26848/rbgf.v13.1.p322-335

MEDEIROS, W. M. V.; SILVA, C. E.; LINS, R. P. M.. Avaliação sazonal e espacial da qualidade das águas superficiais da bacia hidrográfica do rio Longá, Piauí, Brasil. Revista Ambiente \& Água, Taubaté, v.13, n.3, p.1-17, 2018. DOI: http://dx.doi.org/10.4136/ambi-agua.2054

MELLO, K.; TANIWAKI, R. H.; PAULA, F. R.; VALENTE, R. A.; RANDGIR, T. O.; MACEDO, D. R.; LEAL, C. G.; RODRIGUES, C. B.; HUGHES, R. M.. Multiscale land use impacts on water quality: Assessment, planning, and future perspectives in Brazil. Journal of Environmental Management, v.270, n.110879, 2020. DOI: https://doi.org/10.1016/i.jenvman.2020.110879

MENEZES, J. P. C.; BITTENCOURT, R. P.; FARIAS, M. S.; BELLO I. P.; FIA, R.; OLIVEIRA, L. F. C.. Relação entre padrões de uso e ocupação do solo e qualidade da água em uma bacia hidrográfica urbana. Engenharia Sanitária e Ambiental, v.21, n.3, p.519-534, 2016. DOI: https://doi.org/10.1590/S141341522016145405

MIR, R. A.; GANI, K. M.. Water quality evaluation of the upper stretch of the river Jhelum using multivariate statistical techniques. Arabian Journal of Geosciences, v.12, n.445, 2019. DOI: https://doi.org/10.1007/s12517-0194578-7

MIRANDA, C.; ROSA, L.; BONITO, J.; JÚNIOR, A.; VEIGA, N.; OLIVEIRA, F.; BARROS, B.. Uso e qualidade da água na microbacia hidrográfica do rio Parafuso (Moju, Pará, Brasil). Revista Recursos Hídricos, Lisboa, v.38, n.2, p.51-62, 2017. DOI: http://doi.org/10.5894/rh38n2-cti2

MOLUGARAM, K.; RAO, G. S.. Statistical Techniques for Transportation Engineering. Butterworth-Heinemann, 2017.

MULLER, T.; GRANADA, C. E.; SPEROTTO, R. A.. Qualidade da água de três locais com potenciais fontes de contaminação no Rio Taquari, RS. Rev. Ambient. Água,

Taubaté, v.11, n.1, p.75-84, 2016. DOI:

https://doi.org/10.4136/ambi-agua.1789
OLIVEIRA, E. C.; COSTA, K. U. D.; REIS, W. D.; SANTOS, A. A.; SILVA, W. T. P.. Diagnóstico temporal e espacial da qualidade da água superficial em uma microbacia urbana. Revista Ibero-Americana de Ciências Ambientais, v.9, n.8, p.57-69, 2018. DOI: http://doi.org/10.6008/CBPC21796858.2018.008.0006

OLIVEIRA FILHO, O. B. Q.; TORO, M. A. G.; SILVA, W. C. M.. Caracterização hidrogeoquímica dos sistemas aquíferos Barreiras e Pirabas da região metropolitana de Belém (RMB) e investigação de possíveis misturas entre as águas. Cadernos de Geociência, São Paulo, v.14, n.1-2, p.8-23, 2018.

PAIVA, S. L. P.; NEVES, S. M. A. S.; NEVES, R. J.; MIRANDA, M. R. S.. Ações antrópicas na área de preservação permanente do córrego sangradouro em Cáceres/MT, e suas implicações nos aspectos físico-químico da água. Caminhos da Geografia, Uberlândia, v.16, n.56, p.49-61, 2015.

PAIVA, A. C. E.; NATHÁLIA, N.; RODRIGUEZ, D. A.; TOMASELLA, J.; CARRIELLO, F.; REZENDE, F. S.. Urban expansion and its impact on water security: The case of the Paraíba do Sul River Basin, São Paulo, Brazil. Science of the Total Environment, v.720, n.137509, 2020. DOI: https://doi.org/10.1016/j.scitotenv.2020.137509

PARÁ. Secretaria de Estado de Planejamento, Orçamento e Finanças. Estatísticas Municipais Paraenses: Capanema. Belém: SEPOF, 2011.

PELUSO, J.; ARONZON, C. M.; MOLINA, M. C. R; ROJAS, D. E.; CRISTOS, D.; COLL, C. S. P.. Integrated analysis of the quality of water bodies from the lower Parana River basin with different productive uses by physicochemical and biological indicators. Environmental Pollution, v.263, p.114434, 2020. DOI: https://doi.org/10.1016/i.envpol.2020.114434

PEREIRA, B. W. F.; MACIEL, M. N. M.; OLIVEIRA, F. A.; ALVES, M. A. M. S.; RIBEIRO, A. M.; FERREIRA, B. M.; RIBEIRRO, E. G. $P$.. Uso da terra e degradação na qualidade da água na bacia hidrográfica do rio Peixe-Boi, PA, Brasil. Revista Ambiente \& Água, Taubaté, v.11, n.2, p.472-485, 2016. DOI: http://doi.org/10.4136/ambi-agua.1802

PIAZZA, G. A.; GROTT, S. C.; GOULART, J. A. G.; KAUFMANN, V.. Caracterização espaço-temporal da qualidade das águas superficiais dos mananciais de abastecimento de Blumenau/SC. REGA, Porto Alegre, v.14, n.8, 2017. DOI: http://doi.org/10.21168/rega.v14n8

PIMENTA, S. M.; BOAVENTURA, G. R.; RIBEIRO, T. G.; PENA A. P.. Eutrofização: aspectos conceituais, usos da água e diretrizes para a gestão ambiental. Revista Ibero-Americana de Ciências Ambientais, Aquidabã, v.6, n.1, p.78-94, 2015. DOI: http://dx.doi.org/10.6008/SPC21796858.2015 .001 .0007

PIRATOBA, A. R. A.; RIBEIRO, H. M. C.; MORALES, G. P. GONÇALVES, W. G.. Caracterização de parâmetros de qualidade da água na área portuária de Barcarena, PA, Brasil. Ambiente \& Água, Taubaté, v.12, n.3, p.435-456, 2017. DOI: https://doi.org/10.4136/ambi-agua.1910

RIBEIRO, T. G.; BOAVENTURA, G. R.; CUNHA, L. S.; PIMENTA, S. M.. Estudo da qualidade das águas por meio da correlação 
de parâmetros físico-químicos, bacia hidrográfica do Ribeirão Anicuns. Geochimica Brasiliensis, Porto Alegre, n.30, v.1, p.84-94, 2016. DOI:

http://doi.org/10.21715/GB2358-2812.2016301084

SILVA, M. A.; ARAÚJO, R. R.. Análise temporal da qualidade da água no córrego limoeiro e no Rio Pirapozinho no estado de São Paulo - Brasil. Revista Formação, v.1, n.24, p.182203, 2017. DOI:

https://doi.org/10.33081/formacao.v1i24.4656

SILVA, R. S. B.; SOUSA, A. M. L.; SODRÉ, S. S. V.; VITORINO, M. I.. Avaliação sazonal da qualidade das águas superficiais e subterrâneas na área de influência do Lixão de Salinópolis, PA. Ambiente \& Água, Taubaté, v.13, n.2, e2072, 2018. DOI: https://doi.org/10.4136/ambi-agua.2072

SILVA, K. W. S.; EVERTON, N. S.; MELO, M. A. D.. Aplicação dos índices biológicos Biological Monitoring Working Party e Average Score per Taxon para avaliar a qualidade de água do rio Ouricuri no Município de Capanema, Estado do Pará, Brasil. Rev. Pan-Amaz. Saude, Ananindeua, v.7, n.3, p.13-22, 2016. DOI: http://dx.doi.org/10.5123/S2176$\underline{62232016000300002}$

SIOLI, H.; KLINGE, H.. Solos, tipos de vegetação e águas na Amazônia. In: EGLER, W. A.; SCHWASSMANN, H. O. Limnological studies in the Amazon estuary. Belém: Museu Paraense Emilio Goeldi, 1962. p.27-41.

SOUZA, A. D. G.; SOUZA, A. H.. A influência da área urbana sobre a qualidade da água na bacia hidrográfica do Ribeirão dos Poços (Poços de Caldas, MG). HOLOS Enviroment, v.15, n.2, p.139, 2015. DOI:

http://doi.org/10.14295/holos.v15i2.9441
SOUZA, G. B. N.. Degradação ambiental: ocupação do solo na várzea do rio Ouricuri, Capanema, PA. In: SIMPÓSIO BRASILEIRO DE GEOGRAFIA FÍSICA APLICADA, 10. Anais. Rio de Janeiro: UFRJ, 2003.

TABLA-HERNANDEZ, J.; HERNANDEZ-RAMIREZ, A. G.; MARTINE-TAVERA, E.; RODRIGUEZ-ESPINOSA, P. F.; MANGAS-RAMIREZ, E.. Impacts on water quality by in situ induced ozone-oxygen oxidation in a polluted urban reservoir. Science of the Total Environment, v.735, p.139364, 2020. DOI:

https://doi.org/10.1016/j.scitotenv.2020.139364

TUNDISI, J. G.; MATSUMURA-TUNDISI, T.. Limnologia. São Paulo: Oficina de Textos, 2008.

TUNDISI, J. G.; MATSUMURA-TUNDISI, T.. Recursos Hídricos no Brasil: Impactos e Desafios. In: TUNDISI, J. G.; MATSUMURA-TUNDISI, T.. A água. São Carlos: SCIENZA, 2020. p.65-74.

VIEIRA, A. S. A.; CRISPIM, D. L.; RODRIGUES, R. S. S.; SILVA, I. Q.; PESSOA, F. C. L.. Resposta Hidrológica às mudanças climáticas em Capanema-PA: Um município da Amazônia. Revista GEONORTE, v.9, n.32, p.67-79, 2018. DOI: http://doi.org/10.21170/geonorte.2018.V.9.N.32.67.79

VON SPERLING, M.. Introdução à qualidade das águas e ao tratamento de esgotos. 3 ed. Belo Horizonte: UFMG, 2005.

WHO. World Health Organization. Acceptability aspects: Taste, odour and appearance. In: WHO. World Health Organization. Guidelines for Drinking-water Quality. 4 ed. Incorporating the 1st Addendum. Geneva: WHO, 2017. p.219-230.

A CBPC - Companhia Brasileira de Produção Científica (CNPJ: 11.221.422/0001-03) detém os direitos materiais desta publicação. Os direitos referem-se à publicação do trabalho em qualquer parte do mundo, incluindo os direitos às renovações, expansões e disseminações da contribuição, bem como outros direitos subsidiários. Todos os trabalhos publicados eletronicamente poderão posteriormente ser publicados em coletâneas impressas sob coordenação da Sustenere Publishing, da Companhia Brasileira de Produção Científica e seus parceiros autorizados. Os (as) autores (as) preservam os direitos autorais, mas não têm permissão para a publicação da contribuição em outro meio, impresso ou digital, em português ou em tradução. 